\title{
Astragalus polysaccharides protect cardiac stem and progenitor cells by the inhibition of oxidative stress-mediated apoptosis in diabetic hearts
}

This article was published in the following Dove Press journal: Drug Design, Development and Therapy

\section{Wei Chen' \\ Jing Ju' \\ Yehong Yang ${ }^{2}$ \\ Hao Wang ${ }^{3}$ \\ Wenjie Chen' \\ Xuelan Zhao' \\ Hongying $\mathrm{Ye}^{2}$ \\ Yu Zhang'}

'Department of Geriatrics, Huashan Hospital, Fudan University, Shanghai, China; ${ }^{2}$ Department of Endocrinology, Huashan Hospital, Fudan University, Shanghai, China; ${ }^{3}$ Core Center of Animal Facility, School of Medicine, Fudan University, Shanghai, China
Correspondence: Wei Chen; Yu Zhang Department of Geriatrics, Huashan Hospital, Fudan University, No 12

Wu-lu-mu-qi Road, Shanghai 200040, China

Tel +86 2I 52889997190

+862152889997293

Email chenwei_0424@I63.com; zy_huashan@163.com
Introduction: Diabetic cardiomyopathy is characterized by an imbalance between myocyte death and regeneration mediated by the progressive loss of cardiac stem and progenitor cells (CSPCs) by apoptosis and necrosis due to the activation of oxidative stress with diabetes. In this study, we evaluated the beneficial effect of astragalus polysaccharides (APS) therapy on the protection of CSPCs through its antioxidative capacity in diabetic hearts.

Materials and methods: Streptozotocin (STZ)-induced diabetic mice and heterozygous (SOD2+/-) knockout mice were employed and administered with APS. Ventricular CSPCs were isolated for oxidative evaluation. The abundance, apoptosis and proliferation, reactive oxygen species (ROS) formation, oxidative damage, and SOD2 protein levels and activities were evaluated in ventricular CSPCs.

Results: We confirmed that APS increased the CSPC abundance, reduced the apoptosis of CSPCs, and enhanced the proliferation of CSPCs in both STZ-induced diabetic mice and nondiabetic SOD2+/- mice. In addition, therapy of APS enhanced SOD2 protein levels and enzyme activities, and inhibited ROS formation and oxidative damage of CSPCs from both STZ-induced diabetic mice and nondiabetic SOD2+/- mice.

Conclusion: Our findings demonstrated the positive effect of APS on the rescue of CSPC preservation in diabetes, dependent on the inhibition of oxidative stress-mediated apoptosis.

Keywords: diabetes, cardiac stem cells, cardiac progenitor cells, oxidative stress, cardiomyopathy, oxidation

\section{Introduction}

Accumulating evidence supports the notion that a compartment of multipotent cardiac stem and progenitor cells (CSPCs) are physiologically resident in the heart, leading to the reconstitution of cardiac tissues and the possibility of myocardial regeneration. ${ }^{1,2}$ CSPCs could differentiate into myocytes, endothelial cells, and smooth muscle cells in vivo and in vitro, and play a pivotal role in the maintenance of cardiac repair and myocardial homeostasis. ${ }^{3,4}$ Diabetic cardiomyopathy, regarded as a "cardiac stem cell compartment disease", is characterized by an imbalance between myocytes' death and regeneration mediated by the progressive loss of CSPCs by apoptosis and necrosis due to the activation of oxidative stress with diabetes..$^{2-7}$ Activation of oxidative stress and increased production of mitochondrial reactive oxygen species (ROS) by hyperglycemia is regarded as the major cause of the clinical cardiomyopathy associated with diabetes. ${ }^{8-10}$ Enhanced oxidative stress in diabetes would specifically impair the growth reserve of the heart, and can induce defects in both growth and survival of CSPCs, and subsequently senescence, growth limitation, and enhanced apoptotic death of CSPCs 
in diabetes contribute to the loss of functional myocardial tissue, leading to the onset of diabetic cardiomyopathy and its progression toward heart failure. Therefore, therapies to directly inhibit oxidative stress-mediated apoptosis of the CSPCs, and lead to enhanced CSPC survival, might hold a great cardioprotective potential. ${ }^{11-13}$

Astragalus membranaceus (Huang Qi) is a small, bushy perennial plant the root of which is commonly used in traditional Chinese medicine as an immune stimulant, to strengthen the body against disease, and to increase overall vitality and stamina. Astragalus polysaccharides (APS) are the main effective immune-stimulating and immunomodulatory component of the plant and comprise the uniform polysaccharide fraction obtained after water extraction. The polysaccharides are a mixture of APSI, II, and III. APSI is a heterosaccharide composed of D-glucose, D-galactose, and L-arabinose in molar ratios of 1.75:1.63:1, with an average molecular weight of $36.3 \mathrm{kDa}$. APSII and III are composed of high-molecular-weight dextran that is bonded mainly with $\alpha$ - $(1 \rightarrow 4)$-D-glycosidic linkages and average molecular weights of 12.3 and $34.6 \mathrm{kDa}$, respectively. ${ }^{14}$ Previously, our study showed that APS administration (at the dosage of either $1.0 \mathrm{~g} / \mathrm{kg}$ body weight per day or $2.0 \mathrm{~g} / \mathrm{kg}$ body weight per day) strikingly reversed the systemic hyperglycemia (including reducing levels of blood glucose and glycated hemoglobin $[\mathrm{GHb}]$ ) in streptozotocin (STZ)-induced diabetic mice (DM),${ }^{15} \mathrm{db} / \mathrm{db}$ mice,${ }^{16}$ and nonobese DM, ${ }^{17}$ with the protection of pancreatic islets. ${ }^{17}$ Moreover, APS treatment (at the dosage of either $1.0 \mathrm{~g} / \mathrm{kg}$ body weight per day or $2.0 \mathrm{~g} / \mathrm{kg}$ body weight per day) significantly ameliorated cardiac dysfunction, inhibited myocardiac fibrosis, and protected myocardial ultrastructure well in STZ-induced DM and db/db mice. ${ }^{15,16,18}$ In addition, there was no significant difference between mice with different APS dosages on the effect of APS on DM. ${ }^{15}$

However, it has not been investigated whether APS could exert the direct influence on the protection of CSPCs dependent on the inhibition of oxidative stress in diabetic hearts. Heterozygous (SOD2+/-) knockout mice have a 50\% reduction in SOD2 activity with increased mitochondrial oxidative damage leading to reduced myocardial antioxidant defenses, which exhibit enlarged/dilated hearts and severe cardiomyopathy, and, therefore, have been utilized to explore oxidative stress in diabetic cardiomyopathy. ${ }^{12,13}$ Therefore, STZ-induced heterozygous (SOD2+/-) knockout mice were employed and CSPCs were isolated to test the hypotheses whether APS may improve diabetic cardiomyopathy by inhibiting oxidative stress-mediated apoptosis of the CSPCs in diabetic hearts.

\section{Materials and methods}

\section{Animals and treatments}

The study protocol was approved by the Institutional Animal Care and Use Committee of Shanghai Fudan University Medical Center, conforming to the guidelines of the National Research Council for the care of laboratory animals in research. APS was obtained from Shanghai Institute of Physiology Academia Sinica, China, extracted with optimized techniques using direct water decoration to $90 \%$ purity. ${ }^{14}$ APS included three subtypes: APSI, II, and III. APSI is a heterosaccharide composed of D-glucose, D-galactose, and L-arabinose in molar ratios of 1.75:1.63:1, with an average molecular weight of $36.3 \mathrm{kDa}$. APSII and III are composed of high-molecularweight dextran that is bonded mainly with $\alpha-(1 \rightarrow 4)$ D-glycosidic linkages and have average molecular weights of 12.3 and $34.6 \mathrm{kDa}$, respectively.

Four-week-old male heterozygous SOD2-deficient mice (SOD2+/- with the C57BL/6J background) (20-25 g) were purchased from Jackson Laboratories, Bar Harbor, Maine. Four-week-old male C57BL/6J mice (20-25 g) were obtained from Core Center of Animal Facility, Fudan University, Shanghai. Diabetes was induced at 5 weeks old by a single injection of STZ (intraperitoneally, $60 \mathrm{mg} / \mathrm{kg}$ body weight, Sigma Chemical Co., St Louis, MO, USA) to mice fasted overnight. Three days after STZ administration, mice with a blood glucose level of at least $15 \mathrm{mmol} / \mathrm{L}$ were considered diabetic and were included in the study. After DM induction, mice were administered by gavage with or without APS $(2.0 \mathrm{~g} / \mathrm{kg}$ body weight per day) for 10 weeks.

All group division and the survival were as follows: 1) Normal control (Ctrl): $\mathrm{C} 57 \mathrm{BL} / 6 \mathrm{~J}$ mice with no treatment, $\mathrm{n}=6.2$ ) DM: C57BL/6J mice with STZ injection, $\mathrm{n}=6$. Eight mice were injected with STZ, and only six mice were considered diabetic. 3) SOD2+/-: SOD2+/- mice with no treatment, $\mathrm{n}=6$. 4) DM-SOD2+/-: SOD2+/- mice with STZ injection, $\mathrm{n}=6$. Eight SOD2+/- mice were injected with STZ and all were considered diabetic. Two mice were dead after diabetes induction. 5) APS-DM: C57BL/6J mice with STZ injection and APS treatment, $\mathrm{n}=6$. Seven mice were injected with STZ. Six mice were considered diabetic, and were administered with APS. 6) APS-SOD2+/-: SOD2+/- mice with APS treatment, $n=6.7)$ APS-DM-SOD2+/-: SOD2+/- mice with STZ injection and APS treatment, $\mathrm{n}=6$. Eight SOD2+/- were injected with STZ, and only seven were considered diabetic, and one mouse was dead after diabetes induction. The remaining six mice were treated with APS.

All mice were housed in Shanghai Fudan University Medical Center Animal Facility. Glucose blood levels (monitored 
by Accucheck Roche) and body weight were measured weekly and glycated hemoglobin $(\mathrm{GHb})$ was measured at 6 and 16 weeks of age (Glyco-Tek Affinity Column Method and Helena Lab. Test Kit). At 16 weeks of age, all animals were anesthetized with ketamine $(10 \mathrm{mg} / 100 \mathrm{~g}$, by peritoneal injection), and were tested for echocardiographic measurements. After killing with cervical dislocation, hearts were harvested for ultrastructural evaluations and further experiments.

\section{Ventricular function}

Transthoracic M-mode and 2D echocardiography were performed with the Acuson Sequoia 256 Echocardiography System (Acuson, Mountain View, CA, USA), and left ventricle (LV) hemodynamics were evaluated subsequently.

\section{Isolation of CSPCs}

After killing, hearts were harvested from mice, and were connected to a plastic cannula through the aorta for retrograde perfusion to remove the circulating blood cells, by using modified commercial minimal essential medium
Eagle-Joklik (Worthington Biochemical Corp, Lakewood, USA). The LV was cut into small pieces and these fragments were incubated with collagenase $(0.02 \%$ collagenase II and $0.02 \%$ collagenase IV, Worthington Biochemical Corp), for the removal of cardiomyocytes. All cells were filtered through a $40 \mu \mathrm{m}$ mesh. The single-cell suspension was incubated with the antibody against a mouse c-kit (CPC Epitope, stem cell factor receptor, R\&D) and allophycocyanin-conjugated anti-lineage markers (BD Bioscience Pharmigen). The c-kitpositive cells were collected with immunomagnetic beads coated with anti-mouse immunoglobulin G (IgG). The c-kitpositive and lineage-negative cells were identified and sorted by flow cytometry analysis. Unstained samples were used as controls. As reported, CSPCs were identified by employing an antibody against c-kit. Lineage-negative CSPCs corresponding to c-kit positive were negative for transcription factors (GATA-1, GATA-2), cytoplasmic and membrane proteins specific for cardiac cell lineage (CD34, CD45, CD45RO, CD8, CD20, TER-119), and also cardiac markers. ${ }^{19,20}$ The complete list of allophycocyanin-conjugated anti-lineage markers used in this study is shown in Table 1.

Table I Antibodies for cardiac immature cells (including cardiac stem cells, cardiac progenitors, cardiac precursor cells, and amplifying cells)

\begin{tabular}{|c|c|c|}
\hline Cell markers & Function & Antibody labeling \\
\hline \multicolumn{3}{|l|}{ I. CSPC Epitope } \\
\hline C-kit & Stem cell factor receptor & Conjugated primary $\mathrm{Ab}$ \\
\hline \multicolumn{3}{|c|}{ 2. Hematopoietic Markers } \\
\hline TER-II9 & Erythroid marker & Conjugated primary $\mathrm{Ab}$ \\
\hline GATA-I & Differentiation of blood cells & Conjugated primary $\mathrm{Ab}$ \\
\hline GATA-2 & Differentiation of blood cells & Conjugated primary $\mathrm{Ab}$ \\
\hline $\mathrm{CH} 20$ & B-lymphocyte marker & Conjugated primary $\mathrm{Ab}$ \\
\hline CD45RO & T-lymphocyte subset marker & Conjugated primary $\mathrm{Ab}$ \\
\hline CD8 & T-lymphocyte subset marker & Conjugated primary $\mathrm{Ab}$ \\
\hline CD45 & $\mathrm{HSC} / \mathrm{EC}$ antigen & Conjugated primary $\mathrm{Ab}$ \\
\hline CD34 & Pan-myeloid marker & Conjugated primary $\mathrm{Ab}$ \\
\hline \multicolumn{3}{|c|}{ 3. Transcription factors of cardiac cell lineages } \\
\hline Etsl & Differentiation of ECs & Conjugated primary $\mathrm{Ab}$ \\
\hline MEF2C & Differentiation of cardiomyocytes & Conjugated primary $\mathrm{Ab}$ \\
\hline GATA-4 & Differentiation of cardiomyocytes & Conjugated primary $\mathrm{Ab}$ \\
\hline GATA-5 & Regulator of $\mathrm{Nk} \times 2.5$ & Conjugated primary $\mathrm{Ab}$ \\
\hline GATA-6 & Differentiation of VSMCs & Conjugated primary $\mathrm{Ab}$ \\
\hline \multicolumn{3}{|c|}{ 4. Structural proteins of cardiac cell lineages } \\
\hline$\alpha$-sarcomeric actin & Contractile protein of cardiomyocytes & Conjugated primary $\mathrm{Ab}$ \\
\hline Desmin & Intermediate filament of muscle & Conjugated primary $\mathrm{Ab}$ \\
\hline Connexin 43 & Electrical coupling & Primary/secondary $\mathrm{Ab}$ \\
\hline Cardiac myosin & Contractile protein of cardiomyocytes & Conjugated primary $\mathrm{Ab}$ \\
\hline $\mathrm{N}$-cadherin & Mechanical coupling & Primary/secondary $\mathrm{Ab}$ \\
\hline TGF $\beta$ I receptor & VSMC receptor & Conjugated primary $\mathrm{Ab}$ \\
\hline$\alpha-S M$ actin & Contractile protein of VSMCs & Conjugated primary $\mathrm{Ab}$ \\
\hline flk I & VEGF2 receptor in ECs & Conjugated primary $\mathrm{Ab}$ \\
\hline VWF & Factor VIII receptor in ECs & Conjugated primary $\mathrm{Ab}$ \\
\hline
\end{tabular}

Abbreviations: Ab, antibody; CSPC, cardiac stem/progenitor cells; ECs, endothelial cells; HSC, hematopoietic stem cells; $\alpha-S M, \alpha$ smooth muscle; TGF $\beta$ I, transforming growth factor $\beta 1$; VEGF2, vascular endothelial growth factor 2; VSMCs, vascular smooth muscle cells; VWF, Von Willebrand factor. 


\section{Quantification of CSPCs}

The number of CSPCs per unit area of left ventricular myocardium was counted by the confocal microscopy, whereas the average diameter of CSPCs and the number of CSPCs per unit volume of myocardium were calculated using the Schwartz-Saltykov methodology. ${ }^{5,21}$ The total number of CSPCs in the LV was derived from the product of the number of CSPCs per unit volume in each region and the total left ventricular volume, respectively.

\section{Detection of apoptosis}

The cell apoptosis of ventricular CSPCs was measured using hairpin oligonucleotide probes. Briefly, isolated ventricular CSPCs were treated with protease $\mathrm{K}$ and incubated overnight with biotinylated hairpin probe with a single-base 3 'overhang (hairpin 1, Synthetic Genetics) in the presence of T4 DNA ligase. Ligated oligonucleotides were detected with fluorescein isothiocyanate-avidin and hairpin 1 was utilized for detection of double-strand DNA breaks in apoptotic cells. CSPCs were recognized by c-kit labeling. Hairpin 1-positive CSPCs were identified by flow cytometry, and the number of apoptotic CSPCs per unit volume of myocardium were calculated using the Schwartz-Saltykov methodology. ${ }^{5,21}$

\section{Assessment of proliferation}

The cell proliferation of ventricular CSPCs was determined by immunohistochemistry. The nuclear marker Ki67 antibodies (BD Bioscience Pharmigen) were employed to identify proliferating cells. CSPCs were recognized by c-kit labeling. The experiments were performed using Bio-Rad Radiance 2100 MP multiphoton microscope and ImagePro analysis software. Ki67-positive CSPCs were identified by flow cytometry, and the number of proliferating CSPCs per unit volume of myocardium were calculated using the Schwartz-Saltykov methodology. ${ }^{5,21}$

\section{Detection of ROS}

Superoxide production in CSPCs was measured using the fluorescent dye 5-(6)-chloromethyl-2', $7^{\prime}$-dichlorodihydrofluorescein diacetate (CM-H 2 DCFDA, Invitrogen, Molecular Probes). Briefly, cells were loaded with CM- ${ }_{2}$ DCFDA for 30 minutes. The signal generated by $\mathrm{CM}-\mathrm{H}_{2}$ DCFDA was directly proportional to intracellular $\mathrm{H}_{2} \mathrm{O}_{2}$ and $\cdot \mathrm{OH}$ concentration. Nuclei were stained by Syto17 capable of entering living cells and binding to the DNA. The fluorescence intensity was determined by two-photon microscopy, and the generation of fluorescence calibration curves and the evaluation of cell brightness were measured using InSpeck Microscopy Image Intensity Calibration microspheres (Molecular Probes).
The measurements of ROS formation were performed using Bio-Rad Radiance 2100 MP multiphoton microscope and ImagePro analysis software.

\section{Assessment of oxidative damage}

Oxidative damage in CSPCs was determined by immunohistochemistry. Nitrotyrosine (NT) antibody (from Upstate) was employed to detect the oxidative damage to cytoplasmic proteins in CSPCs. The 8-OH-deoxyguanosine (8-OH-dG) mouse monoclonal antibody (from QED Bioscience) was utilized to determine the oxidative stress in the nuclei in CSPCs. The intensity of 8-OH-dG signals was normalized for the propidium iodide fluorescence to correct for differences in the nuclear fraction included in the region. The measurement was performed using Bio-Rad Radiance 2100 MP multiphoton microscope and ImagePro analysis software.

\section{SOD enzyme activity assay}

Protein concentrations were measured by BCA protein kit (Bio-RAD, Hercules, CA, USA). SOD activities in CSPCs were determined by the Superoxide Dismutase Assay Kit (Trevigen, Gaithersburg, MD, USA), and followed the manufacturer's instructions. The reaction involved xanthine and xanthine oxidase converting nitroblue tetrazolium (NBT) to NBT-diformazan, generating superoxide radicals, and then SOD formed $\mathrm{H}_{2} \mathrm{O}_{2}$ from superoxide radicals. Total SOD activity was determined by the extent of reduction in the appearance of NBT-diformazan. Activity was evaluated using $50-500 \mu \mathrm{g}$ of total cellular protein with $5 \mathrm{mM}$ sodium cyanide $(\mathrm{NaCN})$ to inhibit SOD1 activity. Total SOD activity (reactions not containing $\mathrm{NaCN}$ ) and SOD2 activity (reactions containing $5 \mathrm{mM} \mathrm{NaCN}$ ) in $\mathrm{U} / \mathrm{mg}$ protein were finally calculated in each experimental sample. SOD1 activity was measured by subtracting the SOD2 activity from the total SOD activity.

\section{SOD protein levels}

Protein content of CSPCs from LV was analyzed using Western blots ( $\mathrm{n}=6$ samples per group). Briefly, cells were washed with PBS, and then suspended in $100 \mu \mathrm{L}$ of the lysis buffer $(150 \mathrm{mM} \mathrm{NaCl}, 20 \mathrm{mM}$ Tris-HCl, 1\% Triton X-100, $1 \mathrm{mM}$ EDTA, protease inhibitor cocktail, $10 \mathrm{mM} \mathrm{NaF}$, and $2 \mathrm{mM} \mathrm{Na}_{3} \mathrm{VO}_{4}, \mathrm{pH}$ 7.5). The amount of proteins was valued by the Bio-Rad protein assay (Bio-Rad, Hercules, CA, USA), and then loaded in each lane with equal amount. Separated by $12 \%$ sodium dodecyl sulfate-polyacrylamide gel electrophoresis, the proteins were transferred electrically to a polyvinylidene difluoride membrane. After blocking the membrane with 5\% skim milk, all proteins were immunodetected using 
the rabbit anti-mouse different targeted antibodies. Primary antibodies against SOD1 and SOD2 were purchased from Upstate (USA). Glyceraldehyde 3-phosphate dehydrogenase was detected as loading control. The horseradish peroxidase-conjugated anti-rabbit IgG was applied as the secondary antibody. All protein bands corresponding to targeted antibodies were scanned for quantification of protein expression levels. The densities of the bands in all samples were normalized to the densities of the corresponding bands in the C57BL/6J normal control.

\section{Statistical analysis}

Results are expressed as means \pm SEM from seven replicates. Data were analyzed by one-way analysis of variance and post hoc tests with GraphPad Prism 5 (GraphPad, San Diego, CA, USA). A $P$-value $<0.05$ was considered statistically significant.

\section{Results}

\section{Prevention of hyperglycemia by APS treatment in diabetes}

APS treatment significantly prevented the elevated blood glucose and $\mathrm{GHb}$ levels in $\mathrm{C} 57 \mathrm{BJ} / 6 \mathrm{~J}$ and SOD2+/- mice treated with STZ. In addition to hyperglycemia, the DM lost weight compared to healthy $\mathrm{C} 57 \mathrm{BJ} / 6 \mathrm{~J}$ control mice (Table 2). Similarly, the weight loss in diabetic C57BJ/6J and SOD2+/mice was significantly modified by APS treatment (Table 2 ). Notably, the oxidative stress by partial SOD2 depletion had no influence on blood glucose and $\mathrm{GHb}$ levels, indicating that oxidative stress by partial SOD2 depletion alone might not induce hyperglycemia in the absence of STZ treatment.

\section{Protection of cardiac function by APS in diabetic hearts}

Consistent with our previous study, our findings also showed that the hemodynamic disorder in both the diabetic and the
SOD2+/- mice were significantly modified by the APS treatment $^{21}$ (Figure 1; Table 3).

\section{Rescue of resident CSPCs by APS in diabetic hearts}

As shown in our study, lineage-negative c-kit-positive CSPCs were reduced by $80 \%, 75 \%$, and $85 \%$ in DM, SOD $2+/-$ mice, and diabetic SOD2+/- mice, respectively, compared with that in $\mathrm{C} 57 \mathrm{BJ} / 6 \mathrm{~J}$ control mice (Figure 2). These data indicated that diabetes reduced the abundance of CSPCs, whereas the same reduction of CSPCs was also induced by oxidative stress in hearts with partial SOD2 depletion (Figure 2). However, after APS treatment, there was a nearly 4.1-fold increase shown in CSPCs in DM, 3.8-fold increase in CSPCs in SOD2+/- mice, and 5.5-fold increase in CSPCs in diabetic SOD2+/- mice, respectively (Figure 2). Thus, the reduction of CSPCs by diabetes and/or oxidative stress with partial SOD2 depletion could significantly be reversed by APS treatment in mice. These results suggested that APS treatment might interfere with the impact of diabetes and/or oxidative stress by partial SOD2 depletion on CSPCs, and rescued CSPCs to expand and generate new myocytes, preserving cardiac homeostasis.

\section{Effects of APS on CSPC apoptosis and proliferation in diabetic hearts}

To determine the ongoing apoptotic cell death, left ventricular myocardium was subjected to the ligation of hairpin oligonucleotide probes in situ. Our data showed that CSPC apoptosis in the LV was almost 10-, 9-, and 10.5-fold in DM, SOD2+/- mice, and diabetic SOD2+/- mice, respectively, in comparison with $\mathrm{C} 57 \mathrm{BJ} / 6 \mathrm{~J}$ control mice. However, the increase in the CSPC apoptosis in DM, SOD2+/- mice, and diabetic SOD2+/- mice was significantly reversed by APS treatment (Figure 3). Our results indicated that CSPCs appeared to be protected by the effects of APS from either diabetes and/or oxidative stress by partial SOD2 depletion.

Table 2 APS inhibited hyperglycemia and weight loss in diabetes

\begin{tabular}{|c|c|c|c|c|c|c|c|}
\hline & Ctrl & DM & APS-DM & SOD2+I- & APS-SOD2 $+I-$ & DM-SOD2+I- & APS-DM-SOD2 $+I-$ \\
\hline Body weight, 8 weeks (g) & $28.1 \pm 0.74$ & $27.1 \pm 0.82$ & $28.4 \pm 0.64$ & $27.8 \pm 0.98$ & $28.6 \pm 0.88$ & $26.9 \pm 1.5$ & $28.5 \pm 0.98$ \\
\hline Fasting blood glucose, 8 weeks (mmol/L) & $5.6 \pm 0.1$ & $17.5 \pm 0.4^{\mathrm{a}}$ & $5.8 \pm 0.2^{b}$ & $5.4 \pm 0.1$ & $5.8 \pm 0.2$ & $18 \pm 0.4^{a}$ & $6 \pm 0.2^{c}$ \\
\hline Body weight, 20 weeks (g) & $33.8 \pm 0.68$ & $23.2 \pm 0.84^{\mathrm{a}}$ & $33.1 \pm 0.52^{b}$ & $34.6 \pm 0.86$ & $35.2 \pm 0.42$ & $22.4 \pm 0.9^{a}$ & $34.8 \pm 0.24^{c}$ \\
\hline $\begin{array}{l}\text { Blood glucose (nonfasting), } 20 \text { weeks } \\
(\mathrm{mmol} / \mathrm{L})\end{array}$ & $6.2 \pm 0.3$ & $24.7 \pm 0.72^{\mathrm{a}}$ & $6.4 \pm 0.1^{b}$ & $6.1 \pm 0.2$ & $6.2 \pm 0.2$ & $25.8 \pm 0.82^{\mathrm{a}}$ & $6.5 \pm 0.1^{c}$ \\
\hline Glycated hemoglobin, 20 weeks (\% standard) & $4.8 \pm 0.3$ & $9.8 \pm 0.7^{\mathrm{a}}$ & $4.7 \pm 0.3^{b}$ & $4.7 \pm 0.2$ & $4.6 \pm 0.1$ & $9.6 \pm 0.6^{\mathrm{a}}$ & $4.9 \pm 0.2^{c}$ \\
\hline
\end{tabular}

Notes: C57BJ/6J and SOD2+/- mice were treated with streptozotocin injection at 6 weeks to induce diabetes. APS was administered continuously for the following 12 weeks. C57BJ/6 J mice were taken as the control. Mice were weighed, and blood glucose and glycated hemoglobin were tested at 8 and 20 weeks. Values are mean \pm SEM. ${ }^{a} P<0.05$ vs $C 57 \mathrm{BJ} / 6$ ) control mice ( $\mathrm{n}=8$ per group), ${ }^{\mathrm{b}} \mathrm{P}<0.05$ vs diabetic mice, ${ }^{c} P<0.05$ vs diabetic SOD $2+/-$ mice.

Abbreviations: APS, astragalus polysaccharides; APS-DM, diabetic mice with APS treatment; APS-DM-SOD2+/-, diabetic SOD2+/- mice with APS treatment; Ctrl, control C57BJ/6] mice; DM-SOD2+/-, diabetic SOD2+/- mice; DM, diabetic mice. 


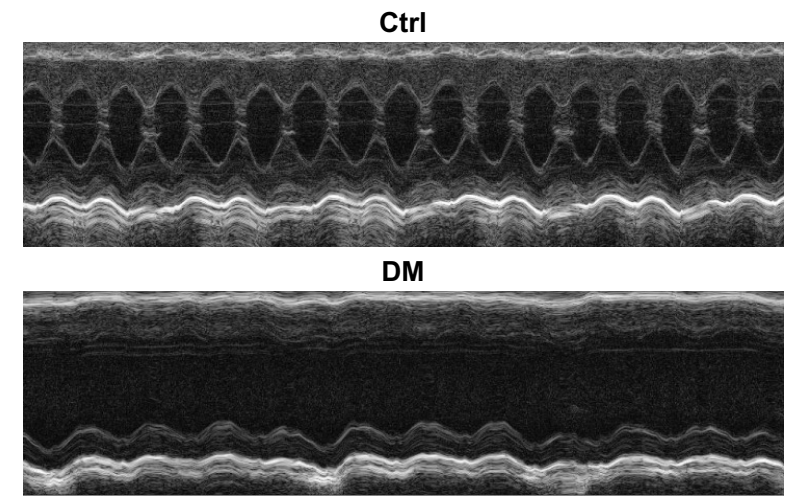

APS-DM

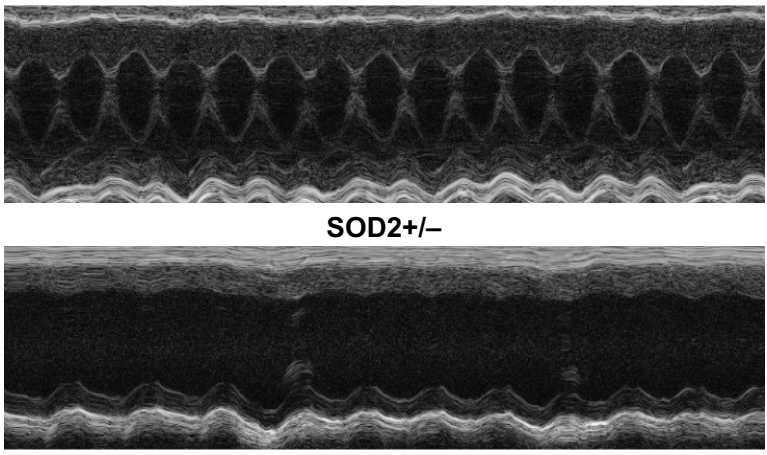

APS-SOD2+1-

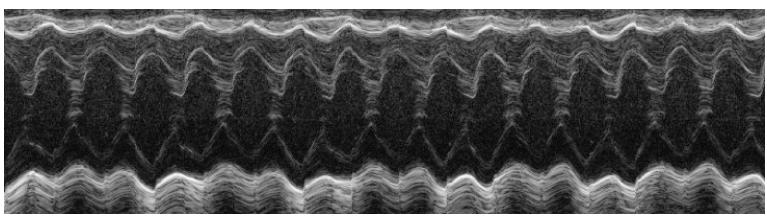

DM-SOD2+/-

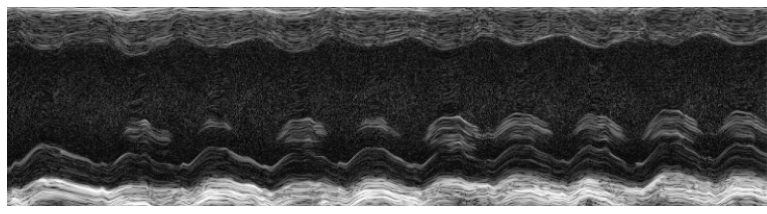

APS-DM-SOD2+/-

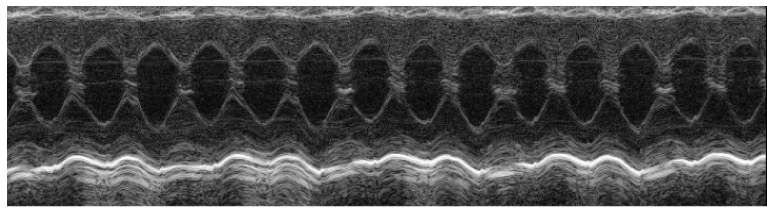

Figure I APS protect cardiac function in diabetes.

Note: Representative echocardiography images of hearts from diabetic or nondiabetic SOD2+l- mice with or without APS treatment ( $n=6$ per group).

Abbreviations: APS, astragalus polysaccharides; APS-DM, diabetic mice with APS treatment; APS-DM-SOD2+/-, diabetic SOD2+/- mice with APS treatment; Ctrl, C57BJ/6J mice were taken as the normal control; DM, diabetic mice; DM-SOD2+/-, diabetic SOD2+/- mice; SOD2+/-, nondiabetic SOD2+/- mice.

Subsequently, Ki67 antibodies were employed in the LV to identify cycling cells. As showed in our study, the percentage of Ki67-labeled CSPCs in LV with diabetes and/or partial SOD2 depletion was decreased by $50 \%$ compared with that in $\mathrm{C} 57 \mathrm{BJ} / 6 \mathrm{~J}$ control hearts, whereas the decrease in CSPC proliferation in hearts with diabetes and/or partial
SOD2 depletion was significantly inhibited by APS treatment (Figure 4). These results raised the possibility that APS treatment positively affected the CSPC division and enhanced CSPC proliferation in hearts with diabetes and/or partial SOD2 depletion.

\section{Reduction in ROS formation by APS in CSPCs in diabetic hearts}

The intracellular levels of hydrogen peroxide $\left(\mathrm{H}_{2} \mathrm{O}_{2}\right)$ and hydroxyl radicals $(\cdot \mathrm{OH})$ were measured to evaluate the ROS formation in CSPCs, which were loaded with CM$\mathrm{H}_{2}$ DCFDA. Compared with that in C57BJ/6J control hearts, the generation of $\mathrm{H}_{2} \mathrm{O}_{2}$ and $\cdot \mathrm{OH}$ nearly doubled in CSPCs from hearts with diabetes and/or with partial SOD2 depletion, whereas after APS treatment, ROS formation did not increase significantly in CSPCs from hearts with diabetes and/or with partial SOD2 depletion (Figure 5). Thus, these data indicated that the ROS formation in CSPCs enhanced by diabetes and partial SOD2 depletion could be mainly attenuated by APS treatment.

\section{Impact of APS on oxidative stress in CSPCs in diabetic hearts}

To explore ROS-mediated cytoplasmic and DNA damage, NT and 8-OH-deoxyguanosine were employed, respectively, in CSPCs (Figure 5). Our data showed that the percentage of both NT-labeled CSPCs and 8-OH-dG-labeled CSPCs was increased by three- to fourfold in hearts with diabetes and/or with partial SOD2 depletion, compared with that in $\mathrm{C} 57 \mathrm{BJ} / 6 \mathrm{~J}$ control hearts, whereas the increase was significantly reversed by APS treatment in hearts with diabetes and/or with partial SOD2 depletion (Figure 5). These results pointed to the reduction in oxidative stress in CSPCs by APS treatment in hearts with partial SOD2 depletion in the absence or presence of diabetes.

\section{Effect of APS on SOD2 enzyme activity and protein level in CSPCs in diabetic hearts and SOD2+/- hearts}

As reported, SOD1 is distributed throughout the cytoplasm and SOD3 is found in extracellular regions, whereas SOD2 is known to be localized only within the mitochondria. ${ }^{12,13}$ Moreover, SOD2 has only one function, which is to dismutate superoxide anion into hydrogen peroxide, which in turn is converted into water and oxygen through the action of catalase or glutathion peroxidase. ${ }^{8}$ Notably, superoxide anion is the precursor of ROS and a potent initiator of an ROS cascade process. ${ }^{10}$ 
Table 3 APS protected heart function in diabetes

\begin{tabular}{|c|c|c|c|c|c|c|c|}
\hline & Ctrl & DM & APS-DM & SOD2+I- & APS-SOD2+I- & DM-SOD2+l- & APS-DM-SOD2+I- \\
\hline LV systolic pressure $(\mathrm{mmHg})$ & $96.1 \pm 2.1$ & $80.5 \pm 3.0^{\mathrm{a}}$ & $95.2 \pm 2.2^{b}$ & $81.6 \pm 2.3^{\mathrm{a}}$ & $96.6 \pm 1.8^{c}$ & $80.5 \pm 3.6^{a}$ & $94.8 \pm 1.2^{\mathrm{d}}$ \\
\hline LV fractional shortening (\%) & $58 \pm 2.8$ & $34 \pm 1.4^{\mathrm{a}}$ & $54 \pm 2.4^{b}$ & $32 \pm 1.3^{\mathrm{a}}$ & $53 \pm 2.3^{c}$ & $30 \pm 1.0^{\mathrm{a}}$ & $50 \pm 2.0^{d}$ \\
\hline LV end-diastolic pressure $(\mathrm{mmHg})$ & $7.4 \pm 1.2$ & $11.6 \pm 3.2^{\mathrm{a}}$ & $7.6 \pm 1.6^{\mathrm{b}}$ & $11.1 \pm 2.4^{\mathrm{a}}$ & $7.0 \pm 1.0^{c}$ & $12.0 \pm 1.8^{\mathrm{a}}$ & $7.2 \pm 0.9^{d}$ \\
\hline LV dP/dt-max (mmHg/s) & $8,142 \pm 477$ & $5,010 \pm 602^{\mathrm{a}}$ & $8,158 \pm 352^{b}$ & $5,125 \pm 424^{a}$ & $8,124 \pm 245^{c}$ & $5,000 \pm 612^{\mathrm{a}}$ & $8,010 \pm 312^{d}$ \\
\hline $\mathrm{LV} \mathrm{dP} / \mathrm{dt}-\mathrm{min}(\mathrm{mmHg} / \mathrm{s})$ & $6,640 \pm 573$ & $4,242 \pm 325^{a}$ & $6,502 \pm 477^{b}$ & $4,4 \mid 2 \pm 288^{a}$ & $6,260 \pm 498^{c}$ & $4,018 \pm 250^{a}$ & $6,3 \mid 2 \pm 388^{d}$ \\
\hline
\end{tabular}

Notes: LV hemodynamics were evaluated in all mice at 16 weeks. Values are mean \pm SEM. ${ }^{a}<0.05$ vs C57BJ/6J control mice ( $n=6$ per group), ${ }^{b} P<0.05$ vs diabetic mice, $c P<0.05$ vs SOD $2+1-$ mice and $d P<0.05$ vs diabetic SOD2+l- mice.

Abbreviations: APS-DM, diabetic mice with APS treatment; APS-DM-SOD2+/-, diabetic SOD2+/- mice with APS treatment; Ctrl, control C57BJ/6] mice; DM, diabetic mice; DM-SOD2+/-, diabetic SOD2+/- mice; LV, left ventricle.

In our present study, we found that diabetes reduced SOD2 but not SOD1 enzyme activities and protein levels in CSPCs, to the extent of the inhibition of SOD2 enzyme activities and protein levels in CSPCs from hearts by partial
SOD2 depletion alone, suggesting that diabetes had negative effect on SOD2 enzyme activities and protein levels in CSPCs (Figure 6). After APS administration, SOD2 enzyme activities and protein levels in CSPCs from either diabetic or

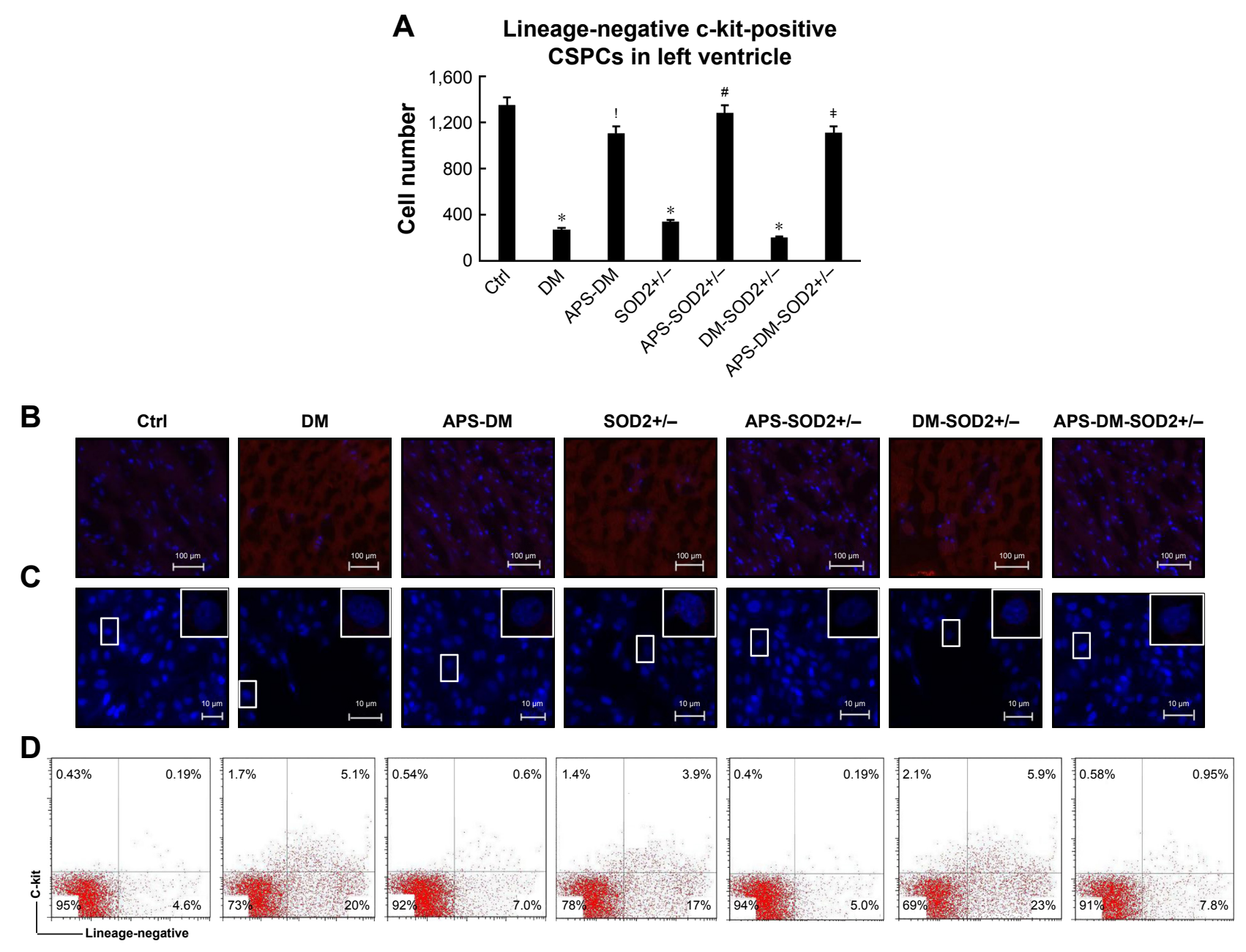

Figure 2 APS increased the abundance of CSPCs in diabetes.

Notes: Left ventricle was obtained from all mice after killing ( $n=6$ per group). CSPCs were recognized by staining for the cell surface marker c-kit, and the c-kit-positive and lineage-negative cells were characterized and sorted by flow cytometry. (A) The number of CSPCs in left ventricle. Ventricular CSPCs were quantified utilizing the Schwartz-Saltykov methodology. Values are mean \pm SEM. $P<0.05$ vs diabetic mice, ${ }^{\# P}<0.05$ vs SOD2+/- mice, ${ }^{\neq} P<0.05$ vs diabetic SOD2+/- mice, and $* P<0.05$ vs $\left.C 57 B J / 6\right]$ control mice. (B) Flow cytometry analysis for the identification of CSPCs. C-kit-positive and lineage-negative cells were gated from total population extracted from the left ventricle and the percentage of CSPC population was analyzed. (C) Confocal microscopy images showing c-kit-positive (blue) and lineage-negative CSPCs by IHC staining for the sections of left ventricle. (D) Confocal microscopy images showing c-kit-positive (blue) and lineage-negative CSPCs by IHC staining for the isolated ventricular CSPCs (original magnification: $\times 8$ million).

Abbreviations: APS, astragalus polysaccharides; APS-DM, diabetic mice with APS treatment; APS-DM-SOD2+/-, diabetic SOD2+/- mice with APS treatment; Ctrl, C57BJ/6] mice were taken as the normal control; DM, diabetic mice; DM-SOD2+/-, diabetic SOD2+/- mice; IHC, immunohistochemistry; SOD2+/-, nondiabetic SOD2+/- mice. 


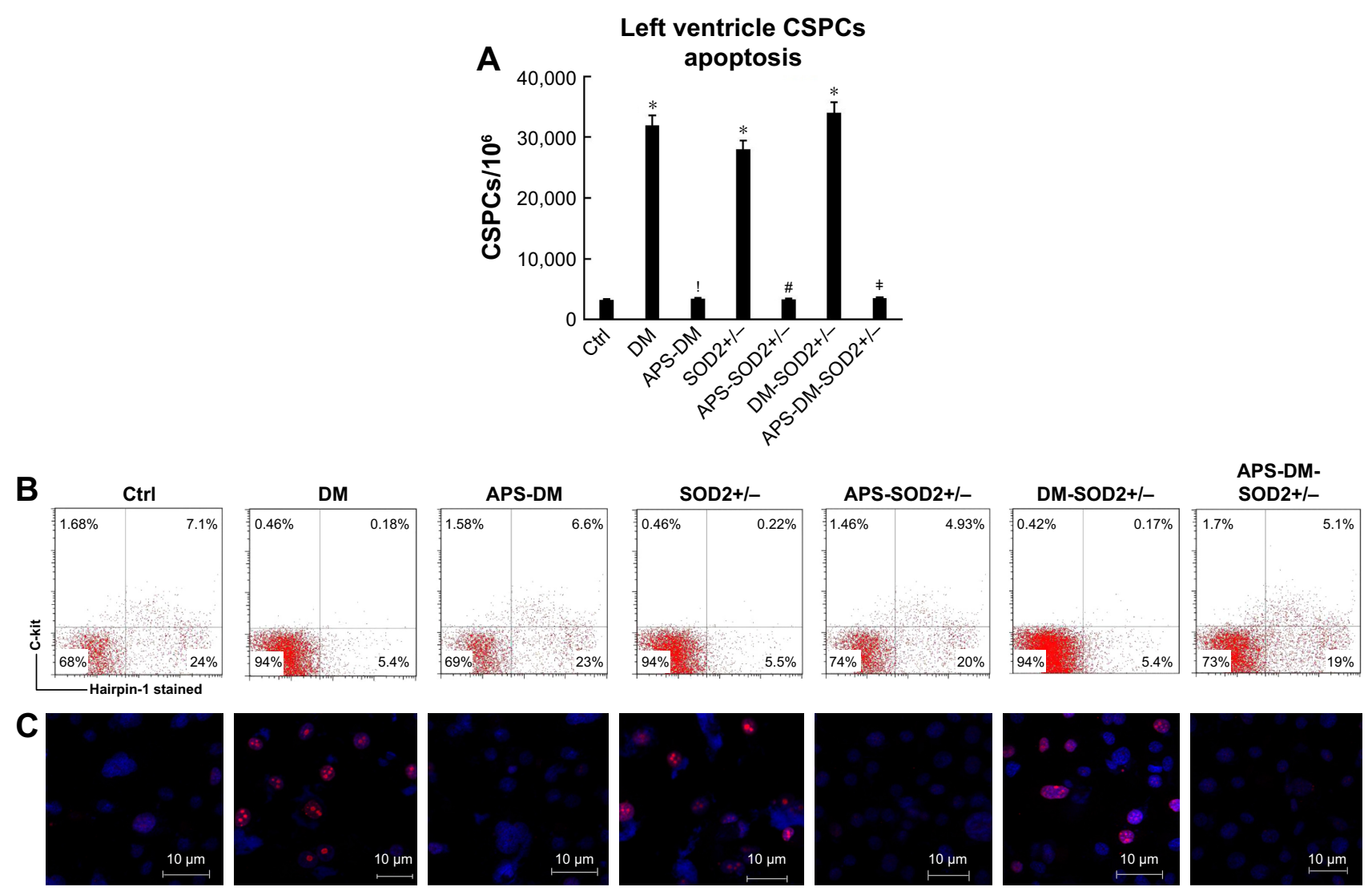

Figure 3 APS inhibited the apoptosis of CSPCs in diabetes.

Notes: Left ventricle was obtained from all mice after killing ( $n=6$ per group). CSPCs were characterized and sorted by flow cytometry. Hairpin oligonucleotide probes were employed for the detection of cell apoptosis. (A) CSPC apoptosis in left ventricle detected by hairpin I; Apoptotic CSPCs were quantified utilizing the Schwartz-Saltykov methodology. Values are mean \pm SEM. $P<0.05$ vs diabetic mice, ${ }^{\# P}<0.05$ vs SOD2+/- mice, ${ }^{\neq} P<0.05$ vs diabetic SOD2+/- mice, and $* P<0.05$ vs $C 57 B J / 6$ J control mice. (B) Flow cytometry analysis for the identification of CSPC apoptosis. Hairpin-I-positive cells were gated from total CSPC population extracted from the left ventricle and the percentage of apoptotic CSPC population was analyzed. (C) Confocal microscopy images showing hairpin I-positive (red) CSPCs in left ventricle. CSPCs were recognized by c-kit labeling (blue) (original magnification: $\times 10$ million).

Abbreviations: APS, astragalus polysaccharides; APS-DM, diabetic mice with APS treatment; APS-DM-SOD2+/-, diabetic SOD2+/- mice with APS treatment; CSPCs, cardiac stem and progenitor cells; Ctrl, C57BJ/6J mice were taken as the normal control; DM, diabetic mice; DM-SOD2+/-, diabetic SOD2+/- mice; SOD2+/-, nondiabetic SOD2+l- mice.

SOD2+/- hearts were significantly elevated to the extent of the levels in CSPCs from the healthy controls. In addition, APS treatment markedly reversed the reduction of SOD2 enzyme activities and protein levels in CSPCs in diabetic SOD2+/- mice, compared with those in C57BJ/6J control mice (Figure 6). Thus, our findings indicated that APS treatment might have beneficial effects on the SOD2 enzyme activities and protein levels in CSPCs, which were mainly adversely affected by diabetes.

\section{Discussion}

Growing evidence supports that the heart possesses a compartment of multipotent stem and progenitor cells (CSPCs), which could differentiate into mature cardiomyocytes and play a pivotal role in the maintenance of cardiac repair and heart homeostasis. ${ }^{2,3}$ The c-kit ${ }^{\mathrm{POS}}$ CSPC pool was the first identified CSPC in rat and human hearts, and is now still the most extensively characterized. Resident adult c-kit ${ }^{\mathrm{POS}} \mathrm{CSPCs}$ are self-renewing, clonogenic, and multipotent, whereas the cardiac precursor cells express transcription factors for early myocyte lineage and then lose the c-kit ${ }^{\mathrm{POS}}$ turning into amplifying cells, which subsequently differentiate into mature cardiomyocytes. ${ }^{22,23}$ Emerging documents demonstrate that the CSPC compartment disease plays an important role in the pathophysiology of diabetic cardiomyopathy. ${ }^{2,3}$ The heart continuously renews itself through the activation of the cell death pathway and inhibition of cell replication, whereas an imbalance between myocyte death and regeneration could result from diabetes and may be mediated by defects in growth and survival of CSPCs. Diabetes alters cardiac homeostasis by producing premature aging, loss of replicative growth, and death of CSPCs, resulting in an excessive number of old, dying, and poorly contracting cardiomyocytes and heart failure. ${ }^{3-5}$ As diabetes specifically impairs the 

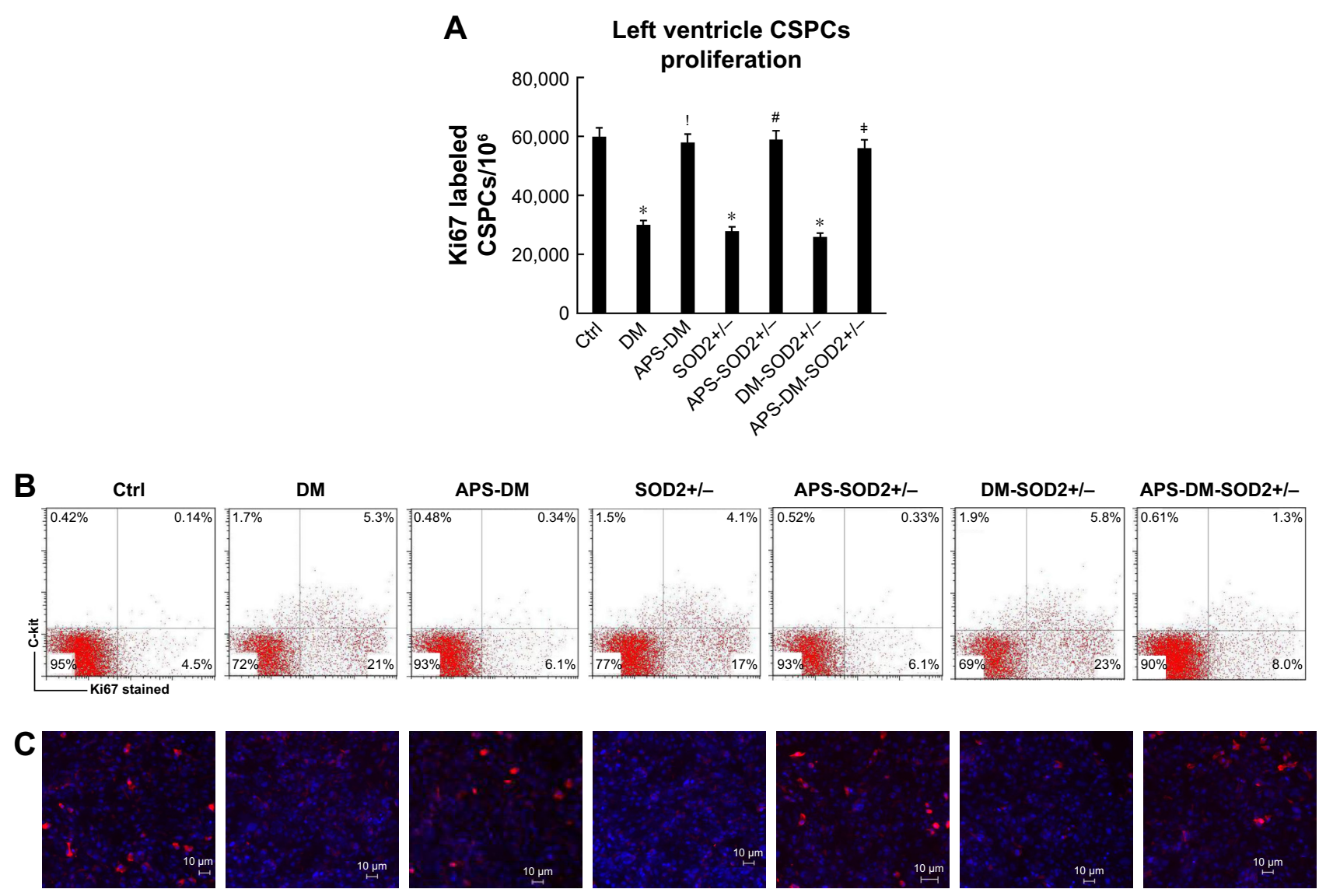

Figure 4 APS enhanced the proliferation of CSPCs in diabetes.

Notes: Left ventricle was obtained from all mice after killing ( $n=6$ per group). CSPCs were characterized and sorted by flow cytometry. The expression of Ki67 was determined for the cell proliferation. (A) CSPC proliferation in left ventricle detected by Ki67. Proliferating CSPCs were quantified utilizing the Schwartz-Saltykov methodology. Values are mean \pm SEM. : $P<0.05$ vs diabetic mice, ${ }^{\# P}<0.05$ vs SOD2+/- mice, ${ }^{\ddagger} P<0.05$ vs diabetic SOD $2+/-$ mice, and $* P<0.05$ vs $C 57 B J / 6$ control mice. (B) Flow cytometry analysis for the identification of CSPC proliferation. Ki67-positive cells were gated from total CSPC population extracted from the left ventricle and the percentage of proliferating CSPC population was analyzed. (C) Confocal microscopy images showing Ki67-positive (red) CSPCs in ventricle. CSPCs were recognized by c-kit labeling (blue) (original magnification: $\times 8$ million).

Abbreviations: APS, astragalus polysaccharides; APS-DM, diabetic mice with APS treatment; APS-DM-SOD2+/-, diabetic SOD2+/- mice with APS treatment; CSPCs, cardiac stem and progenitor cells; Ctrl, C57BJ/6] mice were taken as the normal control; DM, diabetic mice; DM-SOD2+/-, diabetic SOD2+/- mice; SOD2+/-, nondiabetic SOD2+l- mice.

growth reserve of the heart, the enhanced myocyte death cannot be counteracted by the regeneration of cardiomyocytes from CSPCs. The reduction in cell turnover favors cellular senescence and death, and alters cardiac homeostasis, which may finally result in loss of contractile tissue, myocardial hypertrophy, and cardiac fibrosis. ${ }^{6,7,21}$ Our present study demonstrated that diabetes led to a dramatic loss of CSPCs, and apoptosis/necrosis in CSPCs and myocytes, and a decrease of proliferation in CSPCs and myocytes, which together resulted in the development of a cardiac myopathy, characterized by cardiac ultrastructural abnormalities and impaired ventricular function. Thus, diabetic cardiomyopathy may be regarded as a stem-cell cardiomyopathy, in which abnormalities in CSPCs define the life and death of the heart.

Accumulating evidence supports that increased production of mitochondrial ROS is recognized as one of the major causes of diabetic cardiomyopathy. ${ }^{7-10}$ ROS modulate CSPC growth and survival: high levels of oxidative stress trigger cellular damage pathways and are critically involved in CSPC loss. Diabetes-associated cellular senescence and augmented ROS generation may result in a shift in the pattern of cell death from apoptosis to necrosis, promoting fibroblast activation and myocardial dysfunction. Recent studies demonstrate that metabolic impairment, generation of ROS, and enhanced intracellular oxidative stress may finally lead to CSPC dysfunction and death in diabetic hearts. ${ }^{21-23}$ Oxidative stress is enhanced with diabetes and may induce defects in both growth and survival of CSPCs. The resulting imbalance between cell death and cell replacement favors the onset of diabetic cardiomyopathy and its progression toward heart failure. ${ }^{23-26}$ Our present study demonstrated that the ROS formation in CSPCs and myocytes markedly 

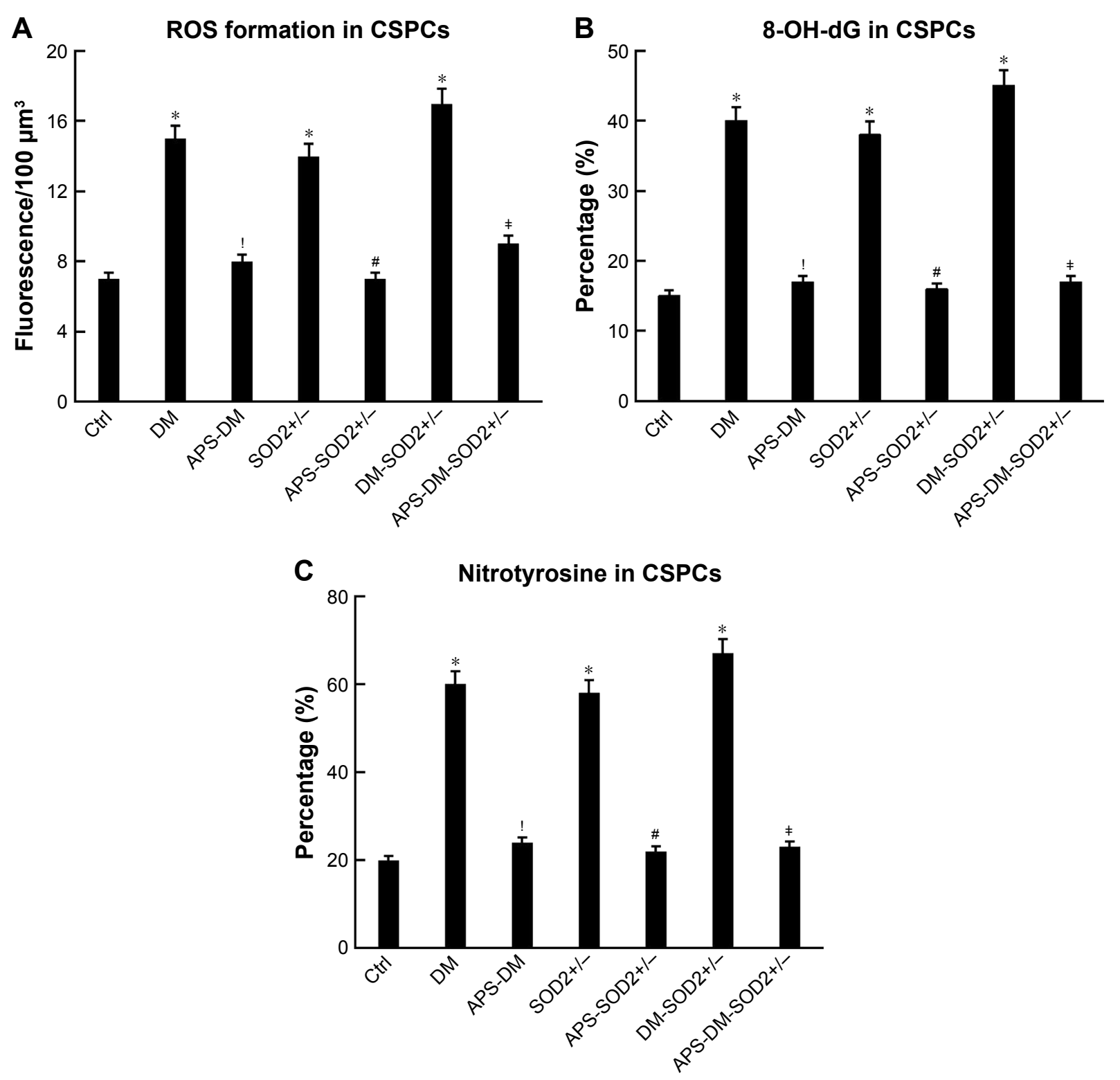

Figure 5 APS inhibited ROS formation and oxidative damage of CSPCs in diabetes.

Notes: Left ventricle was obtained from all mice after killing ( $n=6$ per group). The c-kit-positive and lineage-negative cells were characterized and sorted by flow cytometry. $\mathrm{CM}-\mathrm{H}_{2}$ DCFDA was employed to measure the ROS formation, and the intracellular $\mathrm{H}_{2} \mathrm{O}_{2}$ and $\cdot \mathrm{OH}$ concentrations were analyzed utilizing InSpeak Microscopy Image Intensity Calibration microspheres and ImagePro analysis software. Nitrotyrosine and 8-OH-dG antibodies were employed to detect oxidative damage to cytoplasmic proteins and oxidative stress in the nuclei, respectively. (A) ROS formation in CSPCs in left ventricle. (B) Oxidative stress in the nuclei in CSPCs of left ventricle. (C) Oxidative damage to cytoplasmic proteins in CSPCs of left ventricle. Values are mean \pm SEM. $P<0.05$ vs diabetic mice, ${ }^{\#} P<0.05$ vs SOD2+l- mice, ${ }^{\ddagger} P<0.05$ vs diabetic SOD2+/- mice, and $* P<0.05$ vs C57BJ/6J control mice.

Abbreviations: APS, astragalus polysaccharides; APS-DM, diabetic mice with APS treatment; APS-DM-SOD2+/-, diabetic SOD2+/- mice with APS treatment; $C M-H_{2} D C F D A$, 5-(6)-chloromethyl-2',7'-dichlorodihydrofluorescein diacetate; CSPCs, cardiac stem and progenitor cells; Ctrl, C57BJ/6J mice were taken as the normal control; DM, diabetic mice; DM-SOD2+/-, diabetic SOD2+/- mice; $\mathrm{H}_{2} \mathrm{O}_{2}$, hydrogen peroxide; $\cdot \mathrm{OH}$, hydroxyl radicals; ROS, reactive oxygen species; SOD2+/-, nondiabetic SOD2+/- mice.

enhanced in DM, together with an induction of oxidative damage to cytoplasmic proteins and oxidative stress in the nuclei in CSPCs and myocytes from diabetic hearts. Hence, therapies that can directly inhibit oxidative stress-mediated apoptosis of the CSPCs, leading to enhanced CSPC survival, hold a great cardioprotective potential.

Our current study has demonstrated that APS therapy might have a positive effect on oxidative stress-mediated CSPC damage in diabetic hearts. First, APS administration resulted in an increased abundance of CSPCs, the decreased apoptosis of CSPCs, and enhanced proliferation of CSPCs in diabetic hearts, leading to a marked recovery of ventricular function, indicating that the reduction of the CSPC pool by diabetes could be remarkably prevented by APS treatment, and APS may result in an efficient regeneration of myocytes and protecting the integrity of myocardium by differentiation of CSPCs in 
A

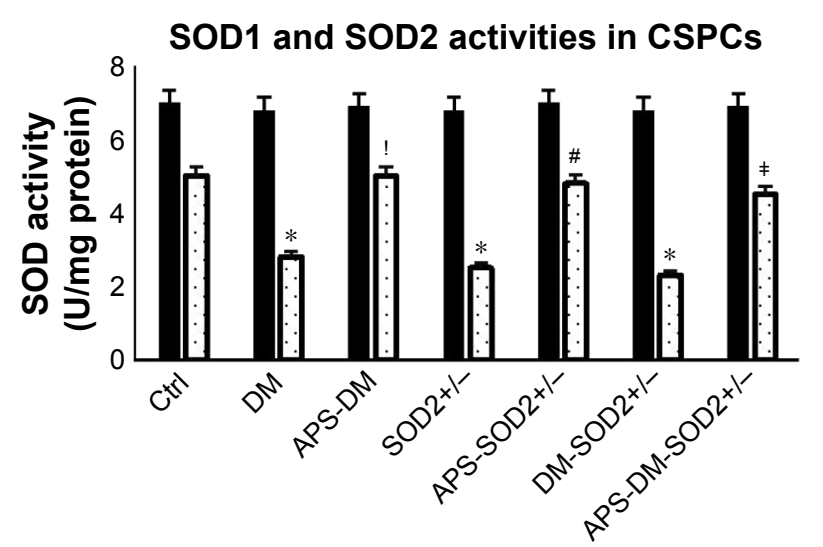

B

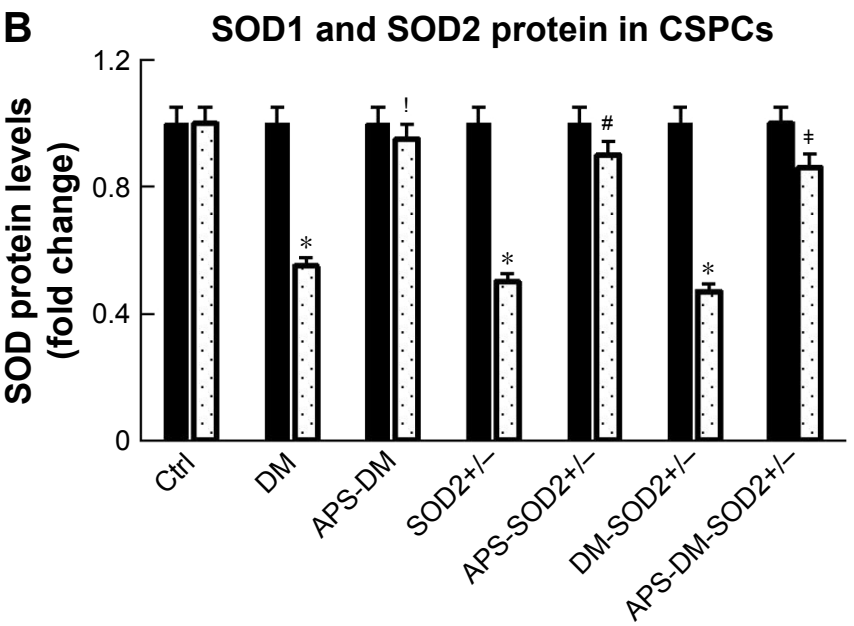

SOD1 口SOD2

C

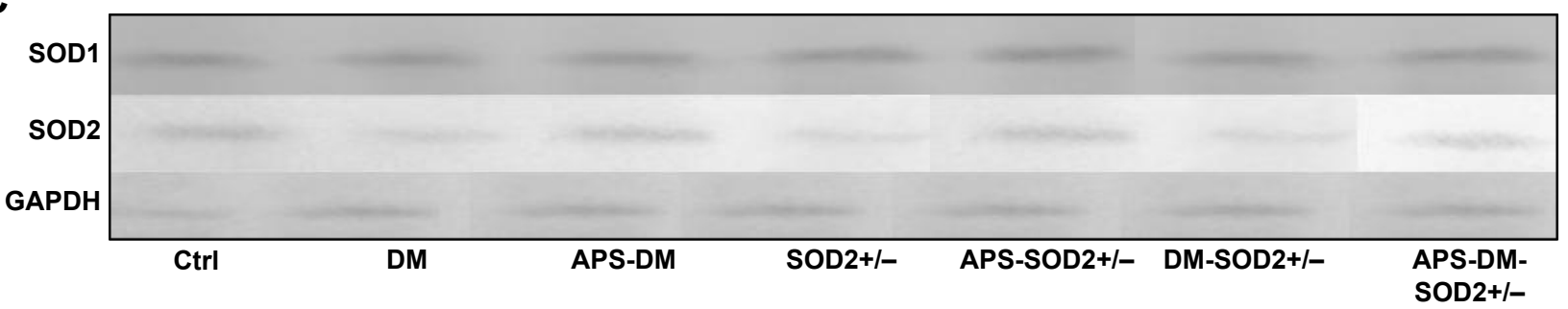

Figure 6 APS enhanced SOD2 enzyme activities and protein levels of CSPCs in diabetes.

Notes: Left ventricle was obtained from all mice after killing ( $n=6$ per group). The c-kit-positive and lineage-negative cells were characterized and sorted by flow cytometry. SOD activity was measured by the extent of reduction in the appearance of nitroblue tetrazolium-diformazan utilizing the Superoxide Dismutase Assay Kit. Total SOD and SOD2 activities in U/mg protein were calculated, and SODI activity was determined by subtracting the SOD2 activity from the total SOD activity. SOD protein levels were analyzed by Western blotting. Membranes were stripped and reprobed for glyceraldehyde 3-phosphate dehydrogenase as a loading control. Protein content was measured and normalized as a ratio relative to the normal control. (A) SODI and SOD2 enzyme activities in CSPCs. (B) Protein levels of SODI and SOD2 in CSPCs. (C) Representative autoradiographs of Western blots. Values are mean \pm SEM. ! $P<0.05$ vs diabetic mice, ${ }^{P} P<0.05$ vs $S O D 2+/-$ mice, ${ }^{\neq} P<0.05$ vs diabetic SOD2+/- mice, and $* P<0.05$ vs $C 57 \mathrm{BJ} / 6$ J control mice.

Abbreviations: APS, astragalus polysaccharides; APS-DM, diabetic mice with APS treatment; APS-DM-SOD2+/-, diabetic SOD2+/- mice with APS treatment; CSPCs, cardiac stem and progenitor cells; Ctrl, C57BJ/6] mice were taken as the normal control; DM, diabetic mice; DM-SOD2+/-, diabetic SOD2+/- mice; SOD2+/-, nondiabetic SOD2+l- mice.

diabetic hearts, preserving cardiac homeostasis. Secondly, APS treatment was shown to decrease NT and 8-OH-dG in CSPCs from STZ-induced diabetic hearts, which indicated that APS administration could inhibit the oxidative damage to cytoplasmic proteins and oxidative stress in the nuclei in CSPCs from diabetic myocardium. Thirdly, APS treatment could mainly reduce ROS formation and the intracellular $\mathrm{H}_{2} \mathrm{O}_{2}$ and $\cdot \mathrm{OH}$ concentrations of CSPCs from diabetic hearts, suggesting that APS administration could definitely prevent diabetes-induced ROS formation in CSPCs. Moreover, APS therapy could valuably enhance the SOD2 enzyme activities and protein levels in CSPCs from STZ-induced diabetic hearts, showing the positive effect of APS on the SOD2 enzyme expression in CSPCs in diabetes. In addition, in nondiabetic SOD2+/- mice, APS treatment could enhance the abundance of CSPCs from the LV, preserve CSPCs with reduced apoptosis and enhanced proliferation, together with the significant improvement of ventricular function, suggesting that APS therapy could directly inhibit oxidative damage to protect CSPCs in diabetic hearts, independent of its effect on hyperglycemia. Finally, in both nondiabetic SOD2+/- mice and diabetic SOD2+/- mice, APS treatment could enhance the abundance of CSPCs from the LV, preserve CSPCs with reduced apoptosis and enhanced proliferation, reduce the oxidative damage and ROS formation in CSPCs, and elevate the SOD2 enzyme activity and protein level in CSPCs, demonstrating the beneficial effect of APS therapy on protection of the CSPCs through the direct inhibition of oxidative stress in diabetic cardiomyopathy, independent of its effect on hyperglycemia.

In conclusion, our findings in the current study demonstrated the positive effect of APS on the rescue of CSPC compartment and the preservation of cardiac homeostasis in diabetes, dependent on its inhibition of oxidative stress in CSPCs. Hence, therapies of APS that can directly inhibit oxidative stress-mediated apoptosis of CSPCs in diabetes hold great cardioprotective potential. 


\section{Acknowledgments}

This study was supported by Chinese State Natural Science Funds Commission (NSFC) Grant No 81473460.

\section{Disclosure}

The authors report no conflicts of interest in this work.

\section{References}

1. Boudina S, Abel ED. Diabetic cardiomyopathy revisited. Circulation. 2007;115:3213-3223.

2. Leonardini A, Avogaro A. Abnormalities of the cardiac stem and progenitor cell compartment in experimental and human diabetes. Arch Physiol Biochem. 2013;119(4):179-187.

3. Huang ZG, Jin Q, Fan M, et al. Myocardial remodeling in diabetic cardiomyopathy associated with cardiac mast cell activation. PLoS One. 2013;8(3):e60827.

4. Katare R, Oikawa A, Cesselli D, et al. Boosting the pentose phosphate pathway restores cardiac progenitor cell availability in diabetes. Cardiovasc Res. 2013;97(1):55-65.

5. Rota M, LeCapitaine N, Hosoda T, et al. Diabetes promotes cardiac stem cell aging and heart failure, which are prevented by deletion of the p66shc gene. Circ Res. 2006;99(1):42-52.

6. Delucchi F, Berni R, Frati C, et al. Resveratrol treatment reduces cardiac progenitor cell dysfunction and prevents morpho-functional ventricular remodeling in type-1 diabetic rats. PLoS One. 2012;7(6):e39836.

7. Laviola L, Leonardini A, Melchiorre M, et al. Glucagon-like peptide-1 counteracts oxidative stress-dependent apoptosis of human cardiac progenitor cells by inhibiting the activation of the c-Jun N-terminal protein kinase signaling pathway. Endocrinology. 2012;153(12):5770-5781.

8. Giacco F, Brownlee M. Oxidative stress and diabetic complications. Circ Res. 2012;107(9):1058-1070.

9. Watanabe K, Thandavarayan RA, Harima M, et al. Role of differential signaling pathways and oxidative stress in diabetic cardiomyopathy. Curr Cardiol Rev. 2010;6(4):280-290.

10. Wold LE, Ceylan-Isik AF, Ren J. Oxidative stress and stress signaling: menace of diabetic cardiomyopathy. Acta Pharmacol Sin. 2005; 26(8):908-917.

11. Vincent AM, Russell JW, Sullivan KA, et al. SOD2 protects neurons from injury in cell culture and animal models of diabetic neuropathy. Exp Neurol. 2007;208(2):216-227.

12. Van Remmen H, Williams MD, Guo Z, et al. Knockout mice heterozygous for Sod 2 show alterations in cardiac mitochondrial function and apoptosis. Am J Physiol Heart Circ Physiol. 2001;81(3): H1422-H1432.
13. Liu C, Ogando D, Bonanno JA. SOD2 contributes to anti-oxidative capacity in rabbit corneal endothelial cells. Mol Vis. 2011;17:2473-2481.

14. Ni Y, Su Q, Liu X. Experimental study of optimized techniques of water decoration extraction of Astragalus polysaccharide. China J Chin Med. 1998;23(6):284-286.

15. Chen W, Yu MH, Li YM, Chen WJ, Xia YP. Beneficial effects of astragalus polysaccharides treatment on cardiac chymase activities and cardiomyopathy in diabetic hamsters. Acta Diabetol. 2010; 47(Suppl 1):S35-S46.

16. Chen W, Xia YP, Zhao XL, et al. The critical role of Astragalus polysaccharides for the improvement of PPAR $\alpha$-mediated lipotoxicity in diabetic cardiomyopathy. PLoS One. 2012;7(10):e45541.

17. Chen W, Li YM, Yu MH. Astragalus polysaccharides: an effective treatment for diabetes prevention in NOD mice. Exp Clin Endocrinol Diabetes. 2008;116:468-474.

18. Chen W, Li YM, Yu MH. Astragalus polysaccharides inhibited diabetic cardiomyopathy in hamsters depending on suppression of heart chymase activation. J Diabetes Complications. 2010;24(3):199-208.

19. Beltrami AP, Barlucchi L, Torella D, et al. Adult cardiac stem cells are multipotent and support myocardial regeneration. Cell. 2003;14: 763-776.

20. Urbanek K, Rota M, Cascapera S, et al. Cardiac stem cells possess growth factor-receptor systems that after activation regenerate the infarcted myocardium, improving ventricular function and long-term survival. Circ Res. 2005;97:663-673.

21. Urbanek K, Torella D, Sheikh F, et al. Myocardial regeneration by activation of multipotent cardiac stem cells in ischemic heart failure. Proc Natl Acad Sci U S A. 2005;102:8692-8697.

22. Aksakal E, Akaras N, Kurt M, et al. The role of oxidative stress in diabetic cardiomyopathy: an experimental study. Eur Rev Med Pharmacol Sci. 2011;15:1241-1246.

23. Poornima IG, Parikh P, Shannon RP. Diabetic cardiomyopathy: the search for a unifying hypothesis. Circ Res. 2006;98:596-605.

24. Aroor AR, Mandavia C, Ren J, Sowers JR, Pulakat L. Mitochondria and oxidative stress in the cardiorenal metabolic syndrome. Cardiorenal Med. 2012;2:87-109.

25. Marchi E, Baldassari F, Bononi A, Wieckowski MR, Pinton P. Oxidative stress in cardiovascular diseases and obesity: role of p66Shc and protein kinase C. Oxid Med Cell Longev. 2013;2013:564961.

26. Mandavia CH, Aroor AR, DeMarco VG, Sowers JR. Molecular and metabolic mechanisms of cardiac dysfunction in diabetes. Life Sci. 2013;92:601-608.
Drug Design, Development and Therapy

\section{Publish your work in this journal}

Drug Design, Development and Therapy is an international, peerreviewed open-access journal that spans the spectrum of drug design and development through to clinical applications. Clinical outcomes, patient safety, and programs for the development and effective, safe, and sustained use of medicines are the features of the journal, which

\section{Dovepress}

has also been accepted for indexing on PubMed Central. The manuscript management system is completely online and includes a very quick and fair peer-review system, which is all easy to use. Visit http://www.dovepress.com/testimonials.php to read real quotes from published authors. 